\title{
ICT-enabled co-production of public services: Barriers and enablers. A systematic review.
}

\author{
Judith Clifton, Daniel Díaz-Fuentes and Gonzalo Llamosas García
}

\begin{abstract}
Information and communication technologies (ICTs) are being heralded by governments and international organizations as a means of augmenting co-production of public services and a number of major initiatives are being rolled out around the world. In parallel to these activities, a body of scholarly work is emerging that investigates the extent to which ICTs enable, or, pose a barrier to, public service co-production. This paper performs the first systematic review of this emerging literature, and provides insights into the main structural and cultural factors which act as an enabler of, or barrier to, ICTenabled co-production across government and citizens world-wide.
\end{abstract}

This is the post-print of the article "ICT-enabled co-production of public services: Barriers and enablers. A systematic review”, by Judith Clifton, Daniel Díaz-Fuentes and Gonzalo Llamosas García, Information Polity, Vol pre-press, no. pre-press, pp. 1-24, 2019, available at IOS Press through http://dx.doi.org/10.3233/IP- 190122 


\section{Introduction}

Do information and communication technologies (ICTs, henceforth) enable, or pose a barrier to, public service co-production? Governments and international organizations often herald ICTs as a new panacea in their quest to augment the co-production of public services by their administrations and citizens (European Commission, 2018; OECD, 2018a). Co-production, conceptualised by Elinor Ostrom and her colleagues at the Workshop in Political Theory and Policy Analysis at Indiana University (Parks et al., 1981), asserts that public services are the joint product of the activities of government officials, individual citizens and communities in the design, management, delivery and/or evaluation of public services, with a view to improve service quality and efficiency (Alford, 2014; Bovaird, 2007; Brandsen \& Pestoff, 2006; Brudney \& England, 1983; Clark, Brudney, Jakobsen, \& Andersen, 2013; Musso, Young, \& Thom, 2019; Osborne, Radnor, \& Strokosch, 2016). Public safety, for example, is not provided by the police alone, rather, it is co-produced by both citizens and police officers in partnership, such as the Neighbourhood Watch scheme (Musso et al., 2019). Co-production, therefore, breaks with the classical view that the government is the sole provider of public services. The co-production concept is often used interchangeably with another concept, co-creation, although some authors argue these are conceptually distinct (Chathoth, Altinay, Harrington, Okumus, \& Chan, 2013). Brandsen \& Honingh (2018) point out how coproduction and co-creation originate in different settings: while co-creation is a new concept associated with marketing, co-production has a longer tradition in the field of public administration. Voorberg et al. (2015) observe that one important difference between co-production and co-creation is associated with the phases of the production cycle. Co-creation typically refers to the active involvement of end-users in the co- 
initiator or co-design phase, whilst co-production tends to refer to the active engagement of citizens in the co-implementation of public services. However, in the public management literature, these differences are rarely appreciated. More often, coproduction and co-creation are used fluidly and interchangeable. In this review, we follow Torfing, Sørensen, \& Røiseland (2016) and Voorberg et al. (2015) in including both concepts in our systematic review of ICT-enabled co-production.

Following from this, "ICT-enabled co-production" is the term commonly used to refer to the use of ICTs to support engagement in the co-production of public services. This may take the form of facilitating traditional forms of co-production of public services (Rodríguez Bolívar, 2015; Webster \& Leleux, 2018), or, of helping establish new ways to co-produce. An example of ICT-enabled co-production supporting traditional coproduction in the health sector would be a doctor's provision of health information effective electronic touchpoints, such as health websites, devices and applications, and patients using these to supplement information about their condition and improve recovery prospects (DonHee, 2017). Electronic consultation practices are considered a means of improving access to the professional when needed (Timmerman et al., 2016). However, ICTs have also allowed the emergence of new kinds of co-production practices, not available traditionally. For example, Wikipedia is a successful example of how citizens can co-produce public goods using ICTs. This co-production practice allows Internet users to enrich contents according to predefined rules and frameworks (Paletti, 2016). Wikipedia provides citizens with free to access knowledge.

ICT-enabled co-production is thought to be attractive for both instrumental and institutional reasons (Meijer, 2012). From an instrumental point of view, deploying ICTs to support co-production may help cut costs, being increasingly attractive in the era of 
budget-strapped governments seeking to innovate and improve public value delivery (Linders, 2012). ${ }^{1}$

Despite the rhetorical enthusiasm, governments have been slower than expected to adopt mechanisms to promote ICT-enabled co-production (Meijer, 2015, OECD, 2018a). In recent years, however, governments have started to roll out ambitious digital programmes in this direction. Examples include the Australian government's Artificial Intelligence (AI) assistant avatar to facilitate access to government services for the disabled (OECD, 2018a), or the United Nations' partnership with Microsoft to launch a social innovation hub to enable young women to start up their own businesses, by supporting them with ICT training and resources (OECD, 2018b).

In response to the rhetoric around ICT-enabled co-production, and governments' emerging efforts to promote it at a large scale in practice, some scholars have expressed skepticism about the effects ICTs will have on co-production processes (Verschuere at al., 2012). For example, Criado and Villodre (2018) have pointed out that, just as ICTs created a "digital divide" as regards telecommunications have/have nots, "ICT-enabled co-production" may do a similar thing, enabling co-production in some scenarios whilst posing a barrier in other contexts, potentially even creating a "double digital divide". This could mean, for example, that particular countries, regions or groups of citizens, could successfully and fruitfully adopt ICT-enabled co-production, whilst others are left behind.

Indeed, even when looking at traditional co-production (without ICTs), a significant body of research had already found co-production to be highly uneven across government and citizens. Commonly cited enablers and barriers to traditional coproduction by government included: funding availability and professional skills (Bovaird

\footnotetext{
${ }^{1}$ For example, a co-production initiative entitled TimeBanks may benefit from ICTs as regards participatory budgeting: ICTs facilitate co-production in the sense that the coordination cost may be lower (Cahn \& Gray, 2012; Verschuere et al., 2012).
} 
and Loeffler, 2012); public professional culture (Tuurnas, 2015); and legal and institutional structures (Torvinen and Ulkuniemi, 2016; Williams et al., 2016). As regards citizens, enablers and barriers to public service co-production have been associated with; motivation to engage (Fledderus and Honingh, 2016); demographic factors (Alonso et al., forthcoming); and social capital (Thijssen and Van Dooren, 2015). Given the insights of research on ICTs and the "digital divide" (Criado and Villodre; 2018; Yu et al., 2018), the impact of ICTs on both already-existing, traditional, public service co-production, as well as new initiatives to co-produce, deserve exploration. Whilst, in some cases, ICTs may well facilitate greater and deeper co-production, there may be other cases where ICTs act as a barrier to these processes.

A body of research has emerged, starting slowly from 2000 onwards, but accelerating from the decade starting in 2010, in parallel with the spread of government initiatives to ostensibly promote ICT-enabled co-production (Bonsón et al., 2012; Ho, 2002; Porumbescu, 2016; Tursunbayeva et al., 2017; Uppström and Lönn, 2017; West, 2004). Within this literature, one sub-strand has examined evidence on the ways in which ICTs enable or pose a barrier to co-production (see, for example, Castelnovo, 2016; Da Silva and Albano, 2017; Lecluijze et al., 2015; Meijer, 2012). To date, there has been no systematic review of this literature; hence, the contribution of this paper is to fill this gap, by performing, to the best of our knowledge, the first systematic review on the topic.

Our systematic review identifies the structural and cultural factors that act as barriers to, or enablers of, ICT enabled co-production in the cases of both governments and citizens. We find, for government, the most important factors include financial and technical capacities, legal issues and organizational culture; for citizens, we identify technical skills, demographic factors (particular age and gender), social dynamics, as well as a number of cultural factors associated with citizen trust to be most relevant. 
The rest of the paper is organised as follows. The second section presents the organizational framework which is adapted from Meijer (2015). The third section provides information on the methodology used for the systematic review as well as data collection. The fourth section discusses the findings of the publication characteristics as well as the literature analysis. The final section concludes with a discussion of the main findings and describes the limitations of this research and future lines for research on this topic.

\section{Framework for Analysis}

This paper adapts the framework developed by Meijer (2015) as an organising device when performing the systematic review. First, the analysis of the effect of ICTs on coproduction processes will be separated into two domains: government and citizens. Second, consideration of enablers and barriers to co-production using ICTs will be divided into "structural" and "cultural" considerations. Commonly cited structural barriers to government innovation include financial capacity, technical skills, managerial support and leadership, and legal issues, amongst others (Meijer, 2015). Cultural barriers to innovation inside government are found in their "organizational culture", which may include negative perceptions and fears on the part of government staff about ICTs. These perceptions might be motivated because ICTs are seen to risk changing their routines (Margetts and Dunleavy, 2002), or because staff fear new technologies may undermine their roles. Finally, bureaucracy (formality, hierarchy, uniformity) may hinder the uptake of ICTs to co-produce. Turning to citizens, use of ICTs to co-produce may be hampered by a range of structural factors, including their technical skills and motivations, or citizens' demographic factors, such as their gender and age (Angelini et al., 2016; Max- 
Neef, 2005; Van Deursen and Van Dijk, 2011). Furthermore, citizens may avoid ICTs due to a range of cultural factors, including their reluctance to integrate these practices as a habit into their daily lives, fears that ICTs may invade their privacy, or because they do not trust in government (Fledderus, 2015; Porumbescu, 2016). Third, the consequences of ICTs on co-production will be specified according to what "stage" this is occurring, namely, the design or implementation stages (see also Meijer, 2014). Meijer's (2015) framework also includes analysis of "fixing" and "framing" strategies. Fixing strategies fundamentally refer to the introduction of systems to improve access, overcoming financial and other restrictions, dealing with legal problems and offering training. Framing refers to processes of re-conceptualizing ICT-enabled co-production, for example, by persuading those who resist it that their fears are unfounded. As our study also presents enablers of ICTs in co-production, we adapt his framework, and include in our analysis of government/citizen, structural/cultural and the stage of adoption those factors which have been found to facilitate ICTs in the literature.

\section{Research Method}

\subsection{Systematic literature review approach}

This study uses a systematic and reproducible method of reviewing the literature on coproduction to ensure a more transparent and replicable body of knowledge. It follows the 'Preferred Reporting Items for Systematic Reviews and Meta-Analysis' (PRISMA), that help authors improve the quality of a literature review process (Liberati et al., 2009) using

a framework focused on responding to specific research questions following strict eligibility criteria (Tursunbayeva et al., 2017). First, we identify a number of questions based on a preliminary review of the literature. Second, we extract data from studies that 
deal with the topic, settings and characteristics using a search strategy. Third, we evaluate the studies' quality according to the eligibility criteria and their recommendations. Finally, we include those studies whose evidence is related to the research questions.

\subsection{Search strategy}

This study uses a search strategy to avoid duplication issues. This consists of digging into Scopus and Web of Science, and covering published papers from social science disciplines. This search strategy includes keywords with a particular interest in ICTs, coproduction and the public sector. The search strategy is set up as follows: Title, abstract and keywords = (“co-production" OR “co-creation") AND Title, abstract and keywords $=$ ("artificial intelligence" OR "internet of things" OR "cloud system" OR "ICT" OR "ICT related innovation" OR "digital public service" OR “information and communication technologies" OR "smart cities" OR "digitally-based solutions" OR “social network” OR “open government” OR “online public service” OR "technological innovation" OR “e-government" OR “m-government"). Type of document = scientific articles. Discipline $=$ Social sciences. Language: English. This research yielded 150 articles in Scopus and 273 articles in Web of Science. The final search was run on 11 August 2018. Full text versions of articles were examined by one researcher according to the eligibility criteria. The other researchers interactively checked the sample of the assessed articles to ensure that the eligibility criteria were applied correctly.

\subsection{Eligibility criteria}

The eligibility criteria consist of a set of elements that assess the validity, applicability and comprehensiveness of a study analysis. To do so, the eligibility criteria are formed 
by the inclusion and exclusion criteria which allow to select relevant studies for the systematic review.
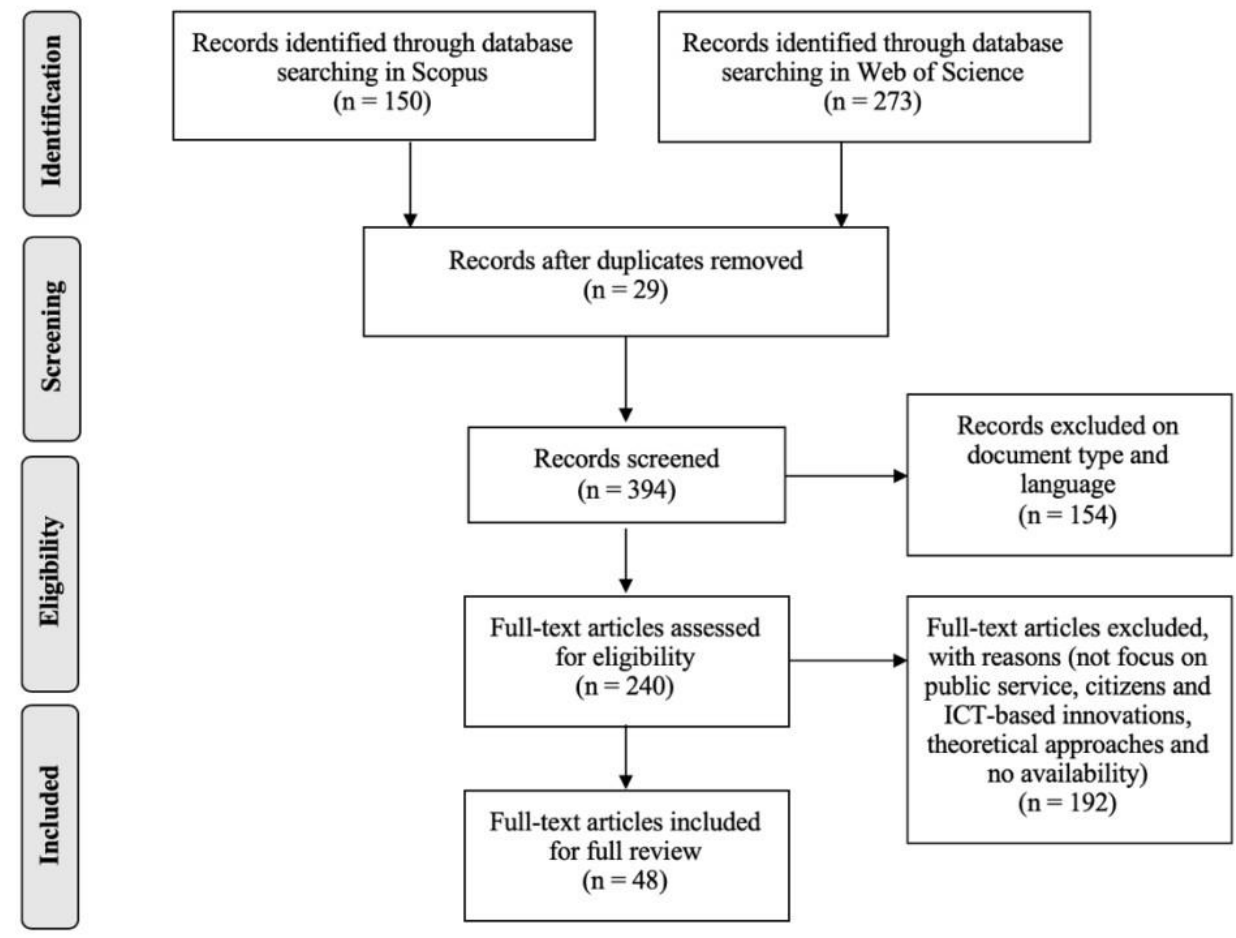

included or full review $(\mathrm{n}=48)$

Figure 1. Flow diagram of the search strategy

On this basis, the set of criteria that have led to the inclusion of 48 studies are as follows:

Inclusion criteria

- $\quad$ Published empirical studies focused on ICT-enabled co-production of public services.

Exclusion criteria

- Studies which are not available in English.

- Studies which are not included in the social science area.

\subsection{Selection of studies}


This section shows the selection process according to the PRISMA statement (Moher et al., 2009). Figure 1 presents a flow diagram that maps out the number of identified, included and excluded records, as well as the reasons for exclusion.

\section{Description of publications}

\subsection{Publication characteristics}

The search strategy generated 423 results, of which 394 were eligible records after removing 29 duplicates. Of these records, 154 were excluded on document type and language. After examining the full texts and excluding articles according to the inclusion and exclusion criteria, 48 qualifying articles remained. These studies were published within a period of 15 years (between 2003 and 2018). We observe that more than three quarters of records were published from 2008 onwards (Figure 2). 19 articles were focused on the health sector, 15 on environment, 15 on education, 12 on government information, 10 on transport and 4 on safety.

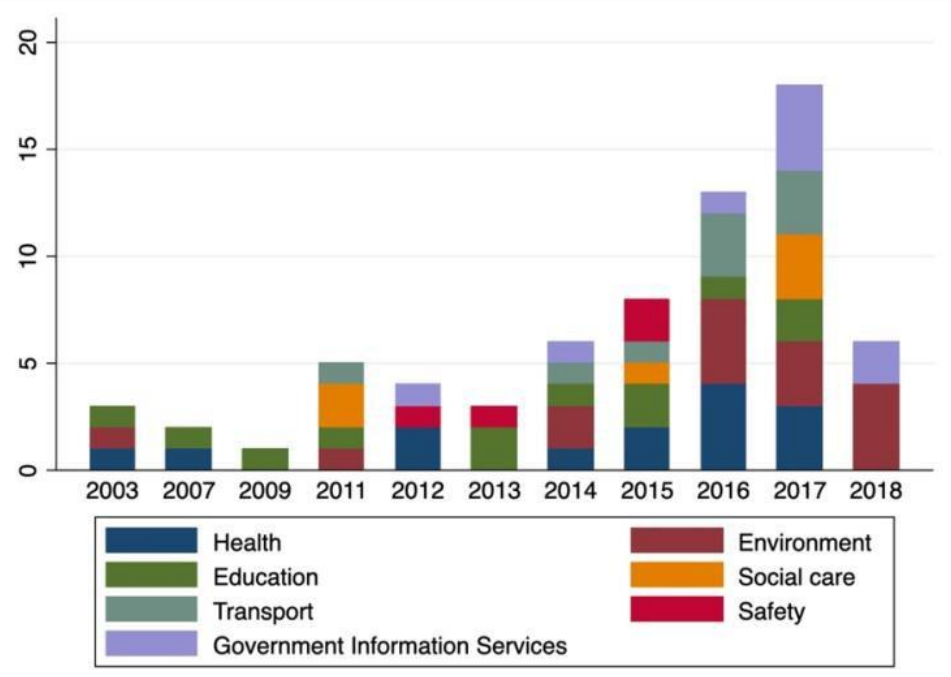

Figure 2. Distribution of published studies by sector and publication year 
Table 1 shows the geographical focus of empirical cases found in articles using regional grouping. According to the distribution of co-production initiatives by regions and countries, we find that Europe concentrates most ICT-enabled co-production initiatives across the world with 39 cases. In Europe, we find that United Kingdom, the Netherlands and Spain were the countries most cited by qualifying articles. According to the UN-EGovernment Survey (United Nations, 2016), United Kingdom is ranked as a global leader on the e-participation index, followed by Japan, Australia, Republic of Korea and the Netherlands. Other countries outside Europe which also were mostly cited in the systematic review were United States and Canada.

Table 1. Distribution of ICT-enabled co-production initiatives by region and country

\begin{tabular}{lclc} 
Region and country & No. Initiatives & Region and countries & No. Initiatives \\
\hline Europe & $\mathbf{3 9}$ & North America & $\mathbf{1 1}$ \\
United Kingdom & 8 & United States & 8 \\
Netherlands & 6 & Canada & 3 \\
Spain & 4 & Asia and Oceania & $\mathbf{4}$ \\
Belgium & 3 & Indonesia & 2 \\
Denmark & 3 & Japan & 1 \\
Finland & 3 & Taiwan & 1 \\
Italy & 2 & Africa & $\mathbf{1}$ \\
Germany & 2 & Zambia & 1 \\
Lithuania & 2 & Latin America & $\mathbf{4}$ \\
Sweden & 2 & Argentina & 1 \\
Greece & 1 & Brazil & 1 \\
Ireland & 1 & Mexico & 1 \\
Norway & 1 & Uruguay & 1 \\
Switzerland & 1 & &
\end{tabular}

Figure 3 shows the most used ICTs in public services' co-production reported by the literature. Our search shows that by far the most frequently mentioned ICT - with 23 
studies referring to it - is social networking. The other most commonly cited ICTs are information management systems (10); mobile phones (7); and e-mail (5).

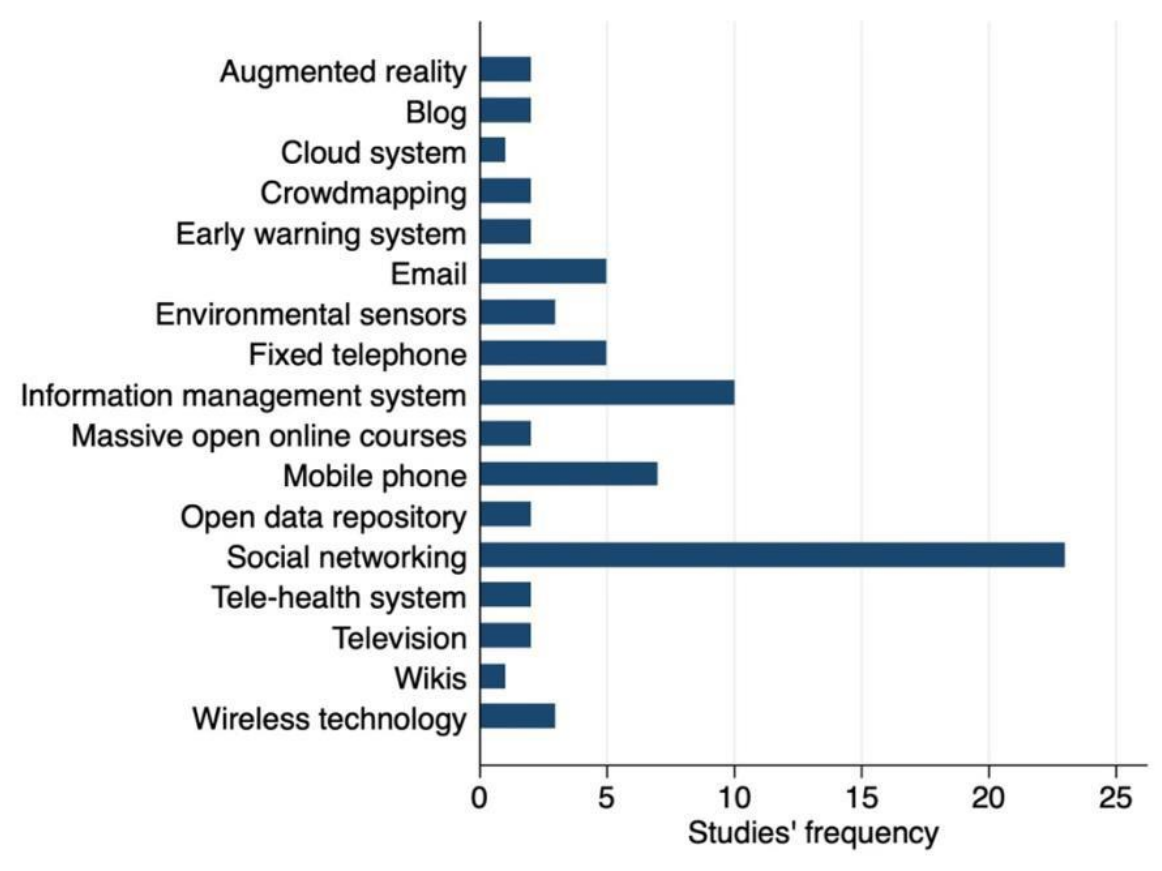

Figure 3. Frequency of studies in terms of ICT types

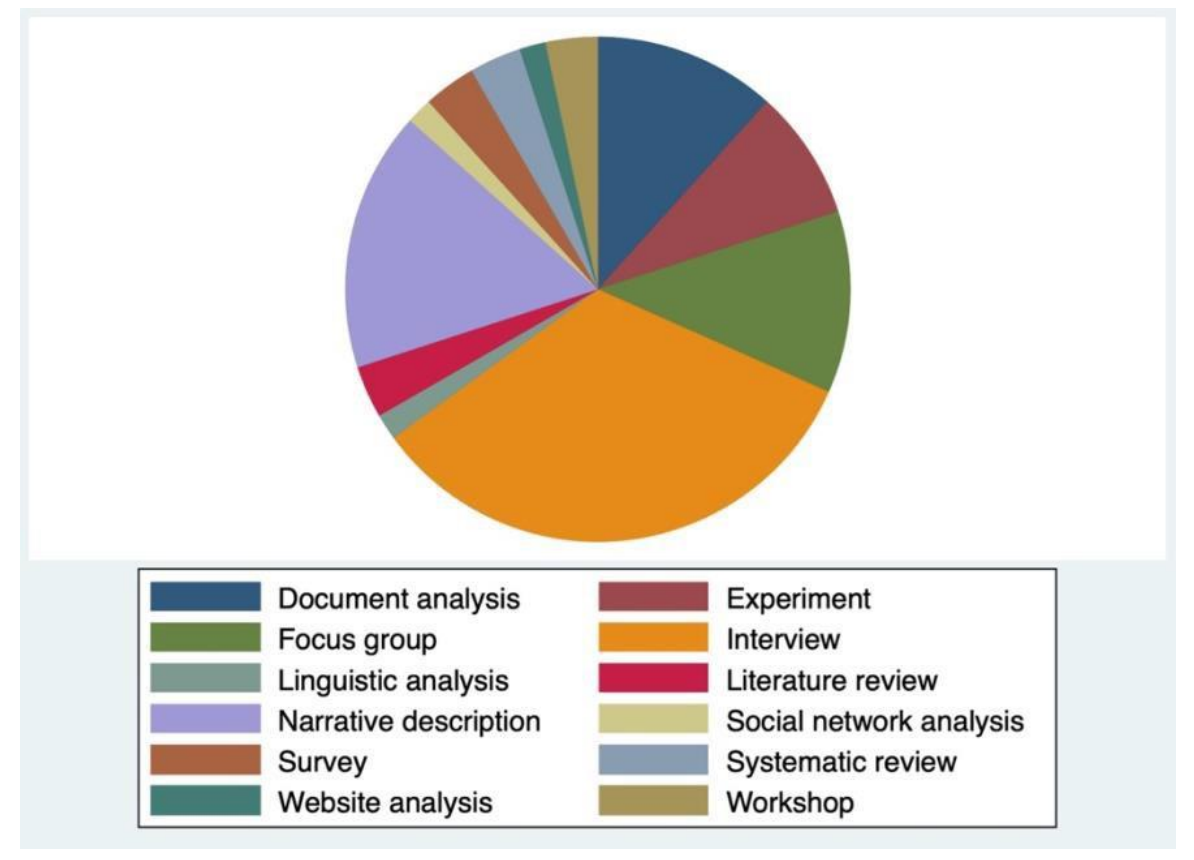

Figure 4. Distribution of studies by research method 
In terms of methodology, the majority of studies are based on qualitative data (Figure 4). In total, 20 studies are based on interviews, which is the most commonly employed research method. Other research methods are narrative descriptions (8); focus groups (7): document analysis (7); and experiments (5).

\section{Findings}

First, we highlight the main factors cited in the literature in the systematic review associated with enabling or posing a barrier to government ICT co-production, after which, we turn to the citizen domain.

\subsection{Government barriers to and enablers of ICT co-production}

Some 25 out of the 48 studies included findings on specific characteristics of government that influence the take-up of ICT-enabled co-production. Table 2 presents information about the government characteristics analysed, as well as the ICT and public sector in question. The most commonly cited structural barriers are financial, technical and legal factors, whereas the most important cultural feature is the organizational characteristics of government. As regards enablers, the most commonly cited were cases where the cost of ICTs are low, reducing the financial risk around failure, and when governments facilitate the engagement of citizens at an early stage of the development process. 


\section{Table 2. Distribution of studies, sectors and ICT typologies at government level}

\begin{tabular}{|c|c|c|c|c|c|c|c|}
\hline \multirow[b]{2}{*}{ \# } & \multirow[b]{2}{*}{ Studies } & \multirow[b]{2}{*}{ ICT type } & \multirow[b]{2}{*}{ Sector } & \multicolumn{3}{|c|}{ Structural government factors } & \multirow[b]{2}{*}{$\begin{array}{c}\text { Government } \\
\text { culture }\end{array}$} \\
\hline & & & & Financial capacities & $\begin{array}{l}\text { Technical } \\
\text { capacities }\end{array}$ & Legal issues & \\
\hline S1 & Amann et al. (2016) & Social networking & Health & $\otimes$ & & $\otimes$ & $\otimes$ \\
\hline S2 & Angelini et al. (2016) & Mobile phone & Health, public transport & $\theta$ & & & \\
\hline s3 & Arto et al. (2016) & - & Health, public transport & & () & & \\
\hline S4 & Baka (2017) & Information management system & Education, health and safety & & $\theta$ & $\otimes$ & \\
\hline S6 & Brynskov et al. (2018) & Environmental sensors & Environment & () & & & \\
\hline S11 & Da Silva and Albano (2017) & Information management system & Government information service & & $\otimes$ & & \\
\hline s12 & Feller et al. (2011) & $\begin{array}{l}\text { E-mail, open data repository and social } \\
\text { networking }\end{array}$ & $\begin{array}{l}\text { Health, education and government } \\
\text { information service }\end{array}$ & $\otimes$ & & & \\
\hline S15 & Ghanbari et al. (2017) & Mobile phone, wireless technology & Health, public transport & $\otimes$ & & & \\
\hline S18 & Gutiérrez et al., (2018) & $\begin{array}{l}\text { Environment sensors, mobile phone and } \\
\text { wireless technology }\end{array}$ & Education, environment and public transport & & $\ominus$ & & \\
\hline S20 & Henwoord and Hart (2003) & Information management system & Environment, health & & & & $\otimes$ \\
\hline S23 & Khayyat and Bannister (2017) & Open data repository & Government information service & & $\theta \otimes$ & & \\
\hline S24 & Kinawy et al. (2018) & Social networking & Environment & & $\theta$ & & \\
\hline S26 & Lecluijze et al. (2015) & Early warning system & Health & & $\Theta$ & () & $\otimes$ \\
\hline S27 & Linders (2012) & Social networking & $\begin{array}{l}\text { Education, government information service } \\
\text { and health }\end{array}$ & $\ominus$ & & & \\
\hline S28 & Löbel et al. (2016) & Information management system & Environment & & $\otimes$ & $\otimes$ & \\
\hline S30 & Maciuliene (2018) & $\begin{array}{l}\text { Augmented reality, mapping and social } \\
\text { networking }\end{array}$ & Environment & $\ominus$ & & & \\
\hline S32 & Medaglia (2012) & - & Government information service & $\theta$ & & & \\
\hline S33 & Meijer (2012) & $\begin{array}{l}\text { Social networking and telephone (fixed or } \\
\text { mobile) }\end{array}$ & Safety & $\theta$ & & & \\
\hline S34 & Meijer (2015) & $\begin{array}{l}\text { Social networking and telephone (fixed or } \\
\text { mobile) }\end{array}$ & Safety & $\theta \otimes$ & & & $\ominus \otimes$ \\
\hline S39 & Szkuta et al. (2014) & Social networking & Education, health and public transport & $\theta$ & & & \\
\hline S40 & Timmerman et al. (2016) & Tele-healthcare system & Health & & & & $\otimes$ \\
\hline S41 & Trivellato (2017) & $\begin{array}{l}\text { Social networking and information management } \\
\text { system }\end{array}$ & Environment, public transport & $\otimes$ & & & \\
\hline $\mathrm{S} 43$ & Uppström and Lönn (2017) & Information management system & Environment & $\theta$ & $\ominus \otimes$ & $\otimes$ & \\
\hline S46 & Van den Hazel et al. (2012) & Social networking & Health & $\otimes$ & & & \\
\hline S48 & Yaraghi et al. (2015) & Information management system & Health & $\theta \otimes$ & & & \\
\hline
\end{tabular}

Source: Scopus and Web of Science. Coding: $\ominus=$ enabler, $\otimes=$ barrier 


\subsubsection{Financial capacity}

Shortage of finance is a common barrier to a government's promotion of ICT-enabled coproduction: lower cost projects tend to be most successful.

Barriers

- The significant financial resources required to establish and maintain ICT-enabled co-production.

- Politically motivated governments may not prioritise projects promoting ICTenabled co-production.

- A lack of coordination may negatively affect efforts to scale-up locally-based ICT-enabled co-production initiatives to the national level.

Enablers

- Low-cost approaches to ICT-enabled co-production diminishes the financial burden to government.

- Financially autonomous governments, such as local government, face fewer barriers to implementing ICT-enabled co-production projects.

Financial capacity as a barrier to ICT-enabled co-production is discussed in 7 of the papers. Most of these studies examine how financial capacity affects the early stages of ICT-enabled co-production, principally, whether or not it was taken up in the first place. One of the major barriers to government take-up of ICT-enabled co-production, reported in all seven studies, is related to problems surrounding a shortage of finance. Three main kinds of barriers to ICT-enabled co-production are identified. The first barrier is the vast financial resources required to establish and then maintain a major ICT-enabled coproduction initiative, such as an online open innovation community (S1), which may 
spiral upwards as regards costs (S12, S15, S41). The second barrier to finance is political: S46 shows that government's financial priorities are often politically motivated, and when these do not coincide with the ICT initiative, this is likely to be blocked. The third barrier is associated with financial coordination, which may negatively affect efforts to scale up locally-based ICT initiatives to the national level. If budgets are controlled locally, forging collaboration at the national level can be an impediment (S34). Where competition exists among local providers, such as the case of US hospitals, local financial support is highly uneven, complicating the task of financial support to scale up a national ICT initiative (S48).

As regards enabling factors associated with finance, two key issues emerge. Overall, financial impediments to the deployment of ICTs in co-production are reported as lower where governments or public agencies opt to use low-cost ICTs (S2, S6, S27, S32, S48, S43). For example, S32 finds that the use of ICTs such as wikis and social networking are effective in involving citizens and other users in co-producing academic knowledge at a low cost. Should the deployment of ICTs be unsuccessful, governments do not have to bear a high financial risk - in other works, the cost of technological failure is low (S39). In addition, where ICT initiatives are established in a financiallyautonomous community, ICT-enabled co-production is reported to have been successful (S33, S34). For example, S30 demonstrates that the introduction of open-source sharing services in the design of digital platforms allows citizens to access software codes to engage in the development of their own online communities while maintaining government financial requirements relatively low. Finally, the use of low-cost ICTs on part of government in financially autonomous communities has been quite successful in promoting ICT-enabled co-production initiatives. 


\subsubsection{Technical capacities}

Skilled workforce shortages constitute a barrier to ICT-enabled co-production. This can be rectified with adequate improvement in staff training, which also reduces the likelihood of technical failures.

Barriers:

- Poor project execution gives rise to technical errors in the use of ICT-enabled coproduction.

- Lack of planning for the day-to-day ICT use may lead to the failure of ICTenabled co-production initiatives.

Enablers:

- Establishing regular technical training reinforces staff knowledge to support ICTenabled co-production.

- A planning manual that supports staffs on how to act in case of doubt is useful to minimise failures in the process.

The technical capacity of government staff is a highly significant factor when explaining both barriers to and enablers of ICT-enabled co-production in government. Logically, when government-employed staff lack adequate technical capacities, this proves a significant barrier to ICT-enabled co-production projects. Four studies in the systematic review detect major difficulties associated with managing ICTs in government once projects have been installed. These difficulties are linked to an initially badly executed 
implementation of an information management system, whereby technical errors lead to bad decision-making (S43), or a lack of planning for day-to-day use by staff of the system once introduced. For example, where data is complex to manage and staff have not been provided with the necessary knowledge about the tools or a helpdesk (S11, S28), ICTenabled co-production projects are hindered. In another study, staff exhibited strong reluctance to acquire the necessary technical capacities to engage in an Open Government initiative when they had not been given guarantees about plans to make data available in the longer-term (S23).

However, the literature also offers some factors whereby technical capacity of government staff positively develops ICT-enabled co-production. For example, S26 finds that, where staff training is improved, fewer technical failures occur, due to two mechanisms. First, a well-designed work manual that guides staff on how to act in the case of doubt proves useful. Second, the organization of extra training sessions to reinforce staff knowledge is important. These mechanisms have a knock-on effect in that staffs' technical knowledge about software and hardware, and their enhanced pedagogical skills, help them to improve the use of ITCs citizens, which, in turn, reduces technical failure (S23, S43). This is seen in S18, where a set of rewards is introduced within an online platform, OrganiCity, to promote citizens' collection of data using Internet of things devices in order to identify possible errors. Another finding is that the engagement of citizens at an early stage of the development process enables pedagogical action by staff to be more fluid and rapid (S3, S4, S24).

\subsubsection{Legal issues}


Complex regulation can prevent government from taking up ICTs to co-produce. A clearer and well-defined regulatory framework that promotes deployment of ICTs may facilitate co-production.

Barriers:

- When regulation is very complex, governments may require the participation of external agents or experts, increasing the operating costs and time required to implement ICT-enabled co-production projects.

- Regulatory changes may alter the implementation and development of ICTenabled co-production.

Enablers:

- Government support of the introduction of regulation focused on facilitating ICTenabled co-production

Legal issues are a fundamental factor as regards helping and hindering ICT-enabled coproduction projects. As regards barriers, four studies find that when regulation is highly complex, this can prevent governments from taking up ICTs to co-produce. S1 concludes complex issues surrounding required legal changes on data protection and privacy in healthcare caused significant delays in the deployment of ICT solutions in co-production in several countries. Another situation where legal issues present barriers to ICT-enabled co-production is when regulatory changes alter the tasks and organization of the actors involved in the process. For example, S4 finds that legal changes delayed the implementation of a web-based platform across Zambia. In another study, S43 finds that changes in the Swedish Forestry Act require constant updates of eAvverka, a management information system for handling forest-felling applications, that resulted in failures when 
participants used old versions. Finally, legal issues act as barriers to ICT-enabled coproduction when regulation is so complex that it requires the intervention of external consults or legal experts. For example, S28 finds that, as result of a burdensome legislation on environmental and labor protection, the German authorities required the intervention of legal intermediaries to support them in the deployment of ICTs in coproduction.

As regards enablers, one paper establishes a positive relationship between law and ICT-enabled co-production: this is the case of the Dutch government which proactively introduced regulation to fully address concerns about professional confidentiality between practitioners and patients in healthcare services (S26). Highly complex legislation is proven to discourage the deployment of ICTs in co-production and it requires the intervention of external intermediaries as legal advisers. The development of a specific regulatory framework on the use of ICTs in public services concerning data protection and privacy is fundamental to facilitate ICT-enabled co-production.

\subsubsection{Government culture}

Perception on the part of government staff that ICTs are intrusive creates resistance to ICT-enabled co-production. Great efforts to persuade staff of the benefits of ICT-enabled co-production go towards improving this situation.

Barrier:

- Negative attitudes on the part of staff towards ICTs because they feel this is a threat to their professional position.

Enabler: 
- Efforts to convince staff on the advantages of ICTs as an adequate instrument to improve the provision of public services.

A number of papers from the systematic review provide insights into the cultural factors exhibited by government organizations (governments or public agencies) that are associated with being a barrier to or an enabler of ICT-enabled co-production.

Five papers analyse how organizational culture may create resistance to the use of ICT in co-production. Several papers discuss situations in which government staff perceive ICTs as potentially controlling and intrusive, introducing too much rigidity to the organization. For example, S20 finds that midwives perceive medical ICTs such as electronic patient records as a threat hampering their professional position and work organization at the hospital. Other papers (S1, S26, S40) report negative attitudes on the part of physicians to co-produce with patients, expressing a preference to not have to contact patients by email or web-based chats. In another study, police officers are reluctant to use ICTs for co-production with citizens as they felt this diminishes their importance as a service provider (S34).

As regards cultural factors associated with enabling ICT-enabled co-production, government efforts have focused on persuading staff to use ICTs to improve the efficiency of the public service in question. A good illustration is in the police force where efforts convinced professionals working in the safety and justice system that Citizens Net was a better instrument to solve crimes than, for example, television programmes on missing persons (S34).

5.2. Citizen barriers to and enablers of ICT-enabled co-production 
Some 33 out of the 48 studies included findings on specific citizen factors that influence the take-up of ICT-enabled co-production. Table 3 presents the distribution of studies which report information of the citizen factors analysed, the public services in which coproduction takes place, as well as the ICTs involved in the process. The most commonly cited structural barriers included technical skills and demographics (particularly, age and gender), whilst a number of cultural barriers were also discussed, including trust in government and social factors.

\subsubsection{Technical Skills}

A lack of technical skills, along with a negative attitude toward ICTs, tend to reduce the participation of citizens in ICT-enabled co-production. The combination of bottom-up processes and ICT training is key to reduce citizens gap of technological skills.

Barriers:

- Lack of training to prepare citizens for ICT-enabled co-production

- Difficulties in understanding the terms and conditions associated with certain ICTs

Enablers

- Including citizens in the early stage of ICT-enabled co-production enhances their knowledge of ICT use

- Deploying only the most common ICTs, such as telephony, encourages participation of citizens from different demographic backgrounds in ICT-enabled co-production. 
Table 3. Distribution of studies, sectors and ICT typologies at citizen level

\begin{tabular}{|c|c|c|c|c|c|c|c|c|}
\hline \multirow[b]{2}{*}{ \# } & \multirow[b]{2}{*}{ Studies } & \multirow[b]{2}{*}{ ICT type } & \multirow[b]{2}{*}{ Sector } & \multicolumn{3}{|c|}{ Structural citizen factors } & \multicolumn{2}{|c|}{ Citizen culture } \\
\hline & & & & Age & Technical skills & Gender & Trust & Social dynamics \\
\hline S1 & Amann et al. (2016) & Social networking & Health & & & & $\theta$ & \\
\hline S2 & Angelini et al. (2016) & Mobile phone & Health, public transport & $\theta \otimes$ & & & & \\
\hline S5 & Bifulco et al. (2017) & & Environment, public transport & & $\theta$ & & & \\
\hline S7 & Buchmüller et al. (2011) & $\begin{array}{l}\text { E-mail, social networking and telephone } \\
\text { (fixed or mobile) }\end{array}$ & Education, environment, public transport & & & $\theta \otimes$ & & \\
\hline S8 & Burch and Harris (2014) & Massive Open Online Courses (MOOCs) & Education & & & $\theta$ & & $\otimes$ \\
\hline s9 & Chatfield et al. (2013) & Early warning system & Government information service & & & & & $\theta$ \\
\hline s10 & Criado and Villodre (2018) & Social networking & Government information service & & & $\otimes$ & & \\
\hline S11 & Da Silva and Albano (2017) & Information management system & Government information service & & & & $\theta$ & \\
\hline S13 & Ferreira (2017) & Social networking & Education & & & $\theta$ & & \\
\hline S14 & Gao (2018) & Social networking and fixed telephone & Government information service & & $\otimes$ & & & \\
\hline S16 & Granier \& Kudo (2016) & Information management system & Environment & $\otimes$ & $\otimes$ & & $\otimes$ & $\otimes$ \\
\hline S17 & Gutiérrez et al. (2016) & Environmental sensors (IoT) & Environment & & $\Theta$ & & & \\
\hline S19 & Hardill \& Mills (2016) & $\begin{array}{l}\text { E-mail, social networking and mobile } \\
\text { phone }\end{array}$ & Education & $\theta \otimes$ & & & & \\
\hline S20 & Henwoord \& Hart (2003) & Information management system & Environment and Health & & & $\otimes$ & & \\
\hline S21 & Huang (2015) & Massive Open Online Courses (MOOCs) & Education & $\Theta \otimes$ & & & & \\
\hline S22 & Karahasanović et al. (2009) & $\begin{array}{l}\text { Blogs, e-mail, social networking and } \\
\text { television }\end{array}$ & Education & $\ominus \otimes$ & $\otimes$ & & & \\
\hline S23 & Khayyat \& Bannister (2017) & Open data repository & Government information service & & $\otimes$ & & & \\
\hline S25 & King \& Cotterill (2007) & Information management system & Education and health & & $\otimes$ & & $\otimes$ & \\
\hline S27 & Linders (2012) & Social networking & $\begin{array}{l}\text { Education, government information } \\
\text { service and health }\end{array}$ & & & & $\Theta$ & \\
\hline S28 & Löbel et al. (2016) & Information management system & Environment & & & & $\Theta$ & \\
\hline S29 & $\begin{array}{l}\text { Maciulienè and Skarzauskienè } \\
\text { (2016) }\end{array}$ & $\begin{array}{l}\text { Augmented reality, crowd-mapping and } \\
\text { social networking }\end{array}$ & Environment & & $\otimes$ & & $\otimes$ & \\
\hline S31 & Mayangsari and Novani (2015) & - & $\begin{array}{l}\text { Education, health, public transport and } \\
\text { safety }\end{array}$ & & & & & $\ominus$ \\
\hline s33 & Meijer (2012) & $\begin{array}{l}\text { Social networking and telephone (fixed } \\
\text { or mobile) }\end{array}$ & Safety & & & $\otimes$ & $\ominus \otimes$ & \\
\hline S34 & Meijer (2015) & $\begin{array}{l}\text { Social networking and telephone (fixed } \\
\text { or mobile) }\end{array}$ & Safety & & $\ominus$ & & & \\
\hline S35 & Millward (2003) & E-mail, fixed telephone and television & Education & $\ominus \otimes$ & $\otimes$ & & & \\
\hline S36 & Muñoz-Erickson (2014) & Social networking & Environment & & & & & $\otimes$ \\
\hline S37 & Nambisan and Nambisan (2017) & $\begin{array}{l}\text { Information management system and } \\
\text { social networking }\end{array}$ & Health & & $\otimes$ & & & \\
\hline S38 & Roussinos and Jimoyiannis (2013) & $\begin{array}{l}\text { Blogs, social networking and wikis }\end{array}$ & Education & & & & & $\ominus$ \\
\hline S39 & Szkuta et al. (2014) & Social networking & Education, health and public transport & & & & $\theta$ & \\
\hline S42 & Tursunbayeva et al. (2017) & Social networking & Health & & & & & $\theta$ \\
\hline S44 & van den Heerik et al. (2017) & Social networking & Health & & & & & $\theta$ \\
\hline S45 & van der Graaf and Veeckman (2014) & $\begin{array}{l}\text { Cloud system, social networking and } \\
\text { wireless technology n }\end{array}$ & Environment, public transport & & $\theta \otimes$ & & & \\
\hline S47 & Wildevuur and van Dijk (2011) & Tele-healthcare system & Health & $\theta$ & & & & \\
\hline
\end{tabular}

Source: Scopus and Web of Science. Coding: $\ominus=$ enabler, $\otimes=$ barrier 
Twelve studies analyse the relationship between technical skills and citizen ICT-enabled co-production. Five studies find that citizens with fewer technical skills, or a negative attitude towards trying out new ICTs, were less engaged with government ICT-enabled co-production initiatives than citizens with more skills (S14, S16, S25, S29, S37). The major reason for this is that citizens are simply unprepared, technically or psychologically speaking, for specific ICT developments (S22, S45). For example, S45 examines the City of Ghent's promotion of mobile phone-based applications to facilitate citizen coproduction of public services. However, a lack of technical skills or perceived difficulty on the part of the citizen are shown to be a major hindrance to ICT-enabled co-production by citizens (S45). Other factors include difficulties experienced by citizens as regards understanding the terms and conditions of open government data (S23), and a general fear of being humiliated (S35).

The literature also includes mechanisms which may enable citizen ICT-enabled co-production. One key method is to reduce citizens" "gap" of technical skills required by a given technology using a combination of bottom-up processes and technological "push". Including citizens with diverse technical and demographic backgrounds in the early stages of ICT development, for example, within Living Labs and Smart City initiatives, has been found to increase the successful use of ICTs for co-production (S5, S17, S45). Another strategy with a similar aim pursued by co-production initiatives is to only deploy the most commonly used ICTs, such as fixed and mobile telephony, as in the case of Citizens Net (S34).

\subsubsection{Demographics}


Older people and females use ICT-enabled co-production less than their younger and male counterparts. Regardless of age and gender, those citizens possessing technical skills tend to actively use ICTs in public services' co-production.

Barriers:

- Older people who lack technical skills have more trouble using ICTs to coproduce.

- The adoption of ICT in co-production might bring a "second digital gender divide"

- Generational differences: older women tend to use ICTs to co-produce less than younger women

Enablers:

- Government can design ICT training programmes focuses on older people.

- The design of ICTs matters for older people. Co-production may be facilitated through the use of user-friendly ICTs.

- Government policy is an essential instrument to reduce the gender digital divide in ICT-enabled co-production "egalitarian discourse".

The two most commonly cited demographic traits of citizens in the studies are age and gender. As regards the use of ICTs by older people more generally, it is already wellknown that a so-called digital "generational" or "grey" divide exists. In its crudest form, this suggests younger people are more active ICT users than older people. Overall, the systematic review confirms this pattern: of the 7 studies which include the analysis of age, the majority find that, although older people often have a positive attitude towards ICT-enabled co-production, they tend to engage in these activities less frequently than younger people overall. There are, however, many important nuances as regards the 
relationship between age and use of ICTs to co-produce. To fully understand this, other factors, including technical skills, emotional needs, type of technology and the perceived ease of use of the ICT in question also need considering.

One finding common to many studies is that older people who lack technical skills are hindered from using ICTs to co-produce. Experiments conducted at the Swiss Senior Living Lab experimentation, for example, report older people without ICTs skills perceive technologies as being too hard to learn how to use (S2). Similar findings are found in S16, S19, S21, S22 and S35. Older people lacking technical skills are more prone to worry about cyber-crime, as seen in S19. In addition, S35 conducted surveys in a deprived zone of England, and shows older people believed they lacked the skills or were "too old" to use the Internet, and were worried about being humiliated by their grandchildren.

A second, related, finding is that older people lacking technical skills may reject using ICTs to co-produce when they perceive this may reduce their social contact with others. For example, as regards co-production in health, S21 and S35 find older people believe using ICTs might diminish their contact time with health professionals. In the context of energy co-production in Japanese smart cities, S16 finds older people would prefer to co-produce collectively rather than use ICTs to co-produce in an individualistic fashion.

Turning to factors that enable older people's co-production, possessing technical skills seems central. First, when older people have the ICTs required, they can be just as active - and on specific occasions, even more active - than younger people co-producing. This is particularly the case when older people perceive using ICTs to improve social bonding or using their "memory" to improve the world. Technically-skilled older people seem motivated to co-produce with ICTs in order to improve their own personal safety, 
health, and that of their families (S19). For example, a field experiment with older people with dementia in a nursing home showed the potential of communicating to their social circle using a tele-healthcare device, Scottie, in a non-verbal way (S47). Similarly, older people with technical skills are just as likely to use the internet to contact Public Administration, and even more likely to use ICTs to express their political opinion than younger people (S22). Clearly, governments can tailor ICT training with specific consideration for the elderly. Though some studies show cross-generational teaching (by the young to the elderly) can make some older citizens feel ashamed (S35), there are other positive examples where the young successfully help older citizens overcome their fears and negative approaches to technology (S21). A second major factor repeated across the studies is that the design of ICTs matters. Interestingly, older people often reject using technology that appears to be made "for" older people - as this is tantamount to admitting one belongs to this group and is thus "stigmatising" (S2). Instead, co-production may be facilitated when user-friendly, easy-to-operate and universally used ICTs are deployed, such as intuitive touchscreen smartphones.

As regards the relationship between gender and ICT use, the so-called "gender digital divide" - whereby women tend to be less active users of ICTs than men - has been widely explored (Hilbert, 2011). Given this, some scholars have worried that the introduction of ICTs to the co-production process might bring about a "second digital gender divide" (S10).

Two of the studies in the systematic review which considered gender found women were indeed less likely than men to use ICTs to co-produce. This was the case for a range of scenarios, including studies taking into account citizens of different ages and occupations within different ICT sectors. However, to provide a nuanced understanding 
of the relationship between gender and ICT-enabled co-production, other factors, including age, education, profession, and technical skills, also need to be considered.

A first set of studies found women less likely to use ICTs to co-produce than men in diverse scenarios. For example, S10 finds that female public sector workers tend to use less than their male co-workers the most successful social media community, NovaGob, implemented across Spain and Latin America to collaborate and exchange knowledge and create public sector innovation. In a similar vein, S33 finds that females were less likely than males to participate in Citizens Net, an ICT service to co-produce safety. A number of studies present findings on the reasons for which women may resist ICT- enabled coproduction. For example, S20 finds that women working as midwives in the UK Maternity Service actively resisted the introduction of ICTs - in the form of the electronic patient record (EPRs) - because either they perceive they have insufficient time or interest to undertake this, or they believe manager (usually, male) are intent on interfering with their job that is to fundamentally help other women successfully give birth.

A second major finding in the studies is that there is an important generational difference: older women are less likely to use ICTs to co-produce than younger women. So, for example, S7 found that older women often preferred traditional social contact, and, when using ICTs, preferred traditional voice telephony over more recent technologies. Older women expressed their reluctance to use ICTs as these were perceived to encroach on their private lives, adding to existing stress levels.

As regards factors associated with enabling ICT-enabled co-production in the category of gender, youth is central. S7 found young girls at school to be just as motivated as boys to use ICTs for social networking. This finding suggests that any gender digital divide can be broken down through targeted government policy. For example, S13 
demonstrated how strong gender stereotypes around ICT use are still deeply pervasive even among young school children, and that campaigns to attract female students to the Internet are further required to disrupt stereotypes. S8 similarly finds the promotion of "egalitarian discourse" crucial to improving take-up of internet-based open courses by females.

As regards older women, those who possess ICT skills, and are heavily involved in a professional career and/or family, tended to use ICTs to co-produce in specific fields, particularly, with a view to improve the organizational complexity of their lives, such as for physical and psychological health, as well as for emotional connectedness with family (S7).

\subsubsection{Citizen culture}

A number of cultural attributes are shown to be significant as regards citizens' propensity to engage in ICT-enabled co-production. The most commonly cited issues in the literature include trust in government and social and other dynamic aspects.

\section{Trust in Government}

A lack of trust in the government tends to reduce the participation of citizens in ICTenabled co-production.

Barriers:

- Citizens who are suspicious of the government are less likely to engage in ICTenabled co-production. 
- Immigrants and young people are suspicious of staff members and tend to not use ICTs to co-produce with them.

Enablers:

- Adopting policies aimed at enhancing citizen engagement in ICT-enabled coproduction initiatives increases trust in government.

- Including intermediaries in ICT-enabled co-production helps to strengthen trust between citizens and governments.

The image citizens have of governments constitutes an important barrier to ICT-enabled co-production: a lack of trust in government means a citizen is less likely to use ICTs to co-produce (Margetts and Dunleavy, 2002). This relationship is also found in the systematic review, which underlines the centrality of trust in government to achieve ICTenabled co-production. Five studies detected a lack of trust in government impeded citizens from using ICTs to co-produce (S16, S25, S29, S33). For example, S16 finds lack of trust (a fear the government may be manipulating citizens) as a key impediment to the promotion of citizen co-production of energy in Japanese smart cities. In another study, researchers find immigrants and young people were suspicious of the police and avoided using ICTs to collaborate with them (S33).

Where trust in government is greater, studies (six) found that ICT-enabled coproduction becomes more prevalent. Indeed, some studies find that the active involvement of citizens in public service delivery and trust in government may be positively be correlated in a bidirectional way. S39 demonstrates that the greater the citizen participation in public service delivery, the greater the trust they have in the government. S33 finds that the success of the initiative, Citizens net, in which citizens co-produce with the police to improve the effectiveness of safety services in the 
Netherlands, led to a bolstering of citizen trust in the police. In contrast, S1 and S27 argue that the more citizens trust government, the more they will actively participate in government ICT-enabled co-production initiatives. Other studies highlight the important role of intermediaries as a "bridge" of expert knowledge that help to strengthen trust between citizens and government through ICTs (S11, S28). For example, S28 shows that in specific cases that are highly complex legally and technically, such as the one that affects environmental protection regulations in Germany, the involvement of intermediaries or experts on these issues improved the relationship of mutual trust with the government by using a common technical language.

Social dynamics

ICT-enabled co-production may be avoided if citizens feel it may disrupt existing social dynamics or where there is an impediment to participation. However, if citizens think coproduction will increase new collaboration, they may accept it.

Barriers:

- Citizens avoid engaging in ICT-enabled co-production when they fear their traditional forms of co-production can be threatened by ICTs.

- Specific ethnic, social and language differences may hinder ICT-enabled coproduction.

Enablers:

- Where ICT-enabled co-production created collaboration, it seems to be more attractive for citizens. 
Social dynamics also influence ICT-enabled co-production. As regards barriers, several papers found that citizens avoid participating in ICT-enabled co-production if they feared their traditional forms of social interaction were threatened by technologies. For example, in the case of the Japanese smart city (S16), older citizens avoided ICT-enabled coproduction because they perceived this replaced more traditional, social and collective form of co-production. Other studies find that specific ethnic, social and language differences may hinder citizen participation in ICT-enabled co-production (S8, S36).

As regards enablers, where ICT-enabled co-production creates collaboration, it may prove attractive to some citizens. For example, S38 finds that highly collaborative groups, rather than groups composed of individual learners, were more likely to be active "wiki" content creators. In other studies, highly collaborative groups constituted an essential form of 'social capital', with a shared sense of identity, and actively engaged in the coproduction of public services (S9, S42, S44, S31). S9 finds that collaborative groups in Indonesia with a shared understanding about disaster situations played a fundamental role in the co-production of time-critical information services on tsunamis and earthquakes using social networking such as Twitter. S44 similarly finds that collaborative groups were able to boost the impact of campaign messages aimed to reduce unhealthy behaviors such as smoking, through the co-production of the health campaign initiated by the Dutch Cancer Society on Facebook and Twitter.

\section{Conclusions}

This paper offers the first systematic review on what we know about the barriers to, and the enablers of, ICT-enabled co-production among government and citizens around the 
word. Policy-makers and politicians have voiced their support for the deployment of ICTs and a number of initiatives have been rolled out. Theoretically speaking, ICT-enabled coproduction of public services is justified by the idea that this can improve the delivery of public services. Before summarizing the findings and pointing out a future research agenda, we mention the limitations of the methodology used in this study, the systematic literature review.

First, with the aim of achieving maximum objectivity, we carefully applied inclusion and exclusion criteria to screen potentially relevant studies for our systematic review. However, there is unavoidable subjectivity in the screening process that may affect the results of the systematic review. Second, although this systematic review covered two important scientific databases, Scopus and Web of Science, it did not cover other sources, such as Google Scholar, which means potentially relevant contributions on the topic may have been missed. Third, this paper relies to a great extent on empirical studies which have relevant policy implications. However, the systematic review methodology offers few possibilities for generalization, making comparison between these studies very difficult. In this vein, further research based on quantitative analysis, such as experiments, could be relevant to obtain greater knowledge. Fourth, though a systematic review provides an overall picture of what has been published on the topic to date (country, sector and type of ICT), policy recommendations cannot be drawn. For example, we have little idea about the relative importance the kind of ICT has upon the potential success of ICT-enabled co-production based on this methodological approach.

As regards our findings, we looked at possible government enablers and barriers affecting ICT-enabled co-production. We distinguished difference between structural and cultural factors first looking at the government side. On the structural side, the key government barriers are associated with shortage of finance, inadequate technical skills 
of staff and complex regulation, including, for example, privacy legislation that is not adapted to share patient data among practitioners. On the cultural side, barriers are associated with resistance of professional staff to use ICTs in co-production. One specific case in point is a medical practitioner, for example, who may be opposed to sharing medical data with patients directly through e-mail or chats. As regards government enablers, these are also associated with structural factors: government selection of lower cost ICT solutions, adequate staff training, and government support to adapt regulation to ICT-enabled co-production. In this regard, the literature provides examples in which governments undertook action to overcome problems associated with the lack of professional confidentiality between practitioners and patients when using different types of ICTs in healthcare services. On the cultural side, the review includes examples of government solutions to restore trust between citizen and governments. For example, one way of strengthening trust in government is through intermediaries or experts as advisers in ICT-enabled co-production initiatives.

On the citizen side, our we found that major barriers are related to demographic factors. Some studies reported that older people and females tend to use ICTs to coproduce less than their younger and male counterparts. To some extent, then, the literature review identifies a "second digital divide" as regards ICT-enabled co-production. In addition to the lack of technical skills, citizens may decline to use ICTs because of their worries and negative emotions around technology, such as the fear of being humiliated by their grandchildren when using them. As regards cultural barriers, a lack of trust in government, specific ethnic, social and language differences, and fearing disruption of traditional forms of social interaction were relevant. Older people may avoid using ICTs if they perceive that these technologies reduce their social contact with other groups of citizens. As regards citizens' enablers, most reviewed studies identify an earlier 
involvement of citizens in ICT-enabled co-production, particularly in the design phase, as a means of encouraging interaction using ICTs. Other enablers consist of running tailored technical training for citizens in order to overcome their barriers to use ICTs. For example, government implementations aimed at designing user-friendly and easy-to-use applications, which are attractive and avoid stigmatizing certain groups of citizens, may encourage citizens to co-produce. Finally, this review shows that citizens are more likely to participate in ICT-enabled co-production when they constitute collaborative groups as a form of social capital, which tends to strengthen trust among participants.

What should the future of this research agenda look like? Both conceptual and methodological advances are required. As regards the first, greater work is needed on the conceptualization of different modalities of ICT-enabled co-production. Beyond categorizing ICT-enabled co-production by the name of the ICT (telephony, social networking, email, etc.), it may be worth categorization by affordability and ease of use, given this review found that the simple and cheaper ICTs tended to face fewer barriers but this finding needs testing and development. As regards the second, future research could aim to apply a quantitative approach to better understanding the barriers to and enablers of ICT-enabled co-production, perhaps by doing experiments. What we found in this review is that a category such as "gender" has no fixed influence as regards a barrier to or enabler of ICT-enabled co-production. Instead, gender needs to be considered alongside other factors, such as education, family situation, work status, and so forth. Hence, experimental approaches are ideal to learn more about the potentially interactive effects of the multiple factors included in this review.

\section{Acknowledgements}


The authors gratefully acknowledge financial support from the European Union's Horizon 2020 research and innovation programme under grant agreement No 726755.

\section{References}

Alford, J. (2014). The Multiple Facets of Co-Production: Building on the work of Elinor Ostrom. Public Management Review, 16(3), 299-316. https://doi.org/10.1080/14719037.2013.806578.

Alonso, J. M., Andrews, R., Clifton, J., \& Díaz-Fuentes, D. (Forthcoming). Factors influencing citizens' co-production of environmental services: a multi-level analysis. Public Management Review. DOI: 10.1080/14719037.2019.1619806

Amann, J., Zanini, C., \& Rubinelli, S. (2016). What online user innovation communities can teach us about capturing the experiences of patients living with chronic health conditions. A scoping review. PLoS ONE, 11(6).

Angelini, L., Carrino, S., Khaled, O. A., Riva-Mossman, S., \& Mugellini, E. (2016). Senior living lab: An ecological approach to foster social innovation in an ageing society. Future Internet, 8(4).

Artto, K., Kyrö, R., Ahola, T., Peltokorpi, A., \& Sandqvist, K. (2016). The Cuckoo's Nest Approach for Co-creating Business Ecosystems in Smart Cities. Technology Innovation Management Review. 
Baka, V. (2017). Co-creating an open platform at the local governance level: How openness is enacted in Zambia. Government Information Quarterly, 34(1), 140-152.

Bifulco, F., Tregua, M., \& Amitrano, C. (2017). Co-governing smart cities through living labs. Top evidences from EU. Transylvanian Review of Administrative Sciences, 2017(50E), 21-37.

Bonsón, E., Torres, L., Royo, S., \& Flores, F. (2012). Local e-government 2.0: Social media and corporate transparency in municipalities. Government Information Quarterly, 29(2), 123-132.

Bovaird, T., \& Loeffler, E. (2012). From Engagement to Co-production: The Contribution of Users and Communities to Outcomes and Public Value. Voluntas, 23(4), $1119-1138$.

Bovaird, T. (2007). Beyond engagement and participation: User and community coproduction of public services. Public Administration Review, 67(5), 846-860.

Brandsen, T., \& Honingh, M. (2018). Definition of Co-production and Co-creation. In T. Brandsen, T. Steen, \& B. Verschuere (Eds.), Co-production and Co-creation: Engaging Citizens in Public Services. Routledge. 
Brandsen, T., \& Pestoff, V. (2006). Co-production, the third sector and the delivery of public services. An introduction. Public Management Review, 8(4), 493-501. https://doi.org/10.1080/14719030601022874.

Brudney, J. L., \& England, R. E. (1983). Toward a definition of the co-production concept. Public Administration Review, (43), 59-65.

Brynskov, M., Heijnen, A., Balestrini, M., \& Raetzsch, C. (2018). Experimentation at scale: challenges for making urban informatics work. Smart and Sustainable Built Environment, 7(1), 150-163.

Buchmüller, S., Joost, G., Bessing, N., \& Stein, S. (2011). Bridging the gender and generation gap by ICT applying a participatory design process. Personal and Ubiquitous Computing, 15(7), 743-758.

Burch, S. L., \& Harris, S. E. (2014). A Massive Open Online Course on climate change: The social construction of a global problem using new tools for connectedness. Wiley Interdisciplinary Reviews: Climate Change, 5(5), 577-585.

Cahn, E., \& Gray, C. (2012). Co-production from a normative perspective. In V. Pestoff, T. Brandsen, \& B. Verschuere (Eds.), New public governance, the third sector and coproduction.

Castelnovo, W. (2016). Co-production makes cities smarter: Citizens' participation in smart city initiatives. SpringerBriefs in Applied Sciences and Technology, 97-117. 
Chatfield, A. T., Scholl, H. J., \& Brajawidagda, U. (2013). Tsunami early warnings via Twitter in government: Net-savvy citizens' co-production of time-critical public information services. Government Information Quarterly, 30(4), 377-386.

Chathoth, P., Altinay, L., Harrington, R. J., Okumus, F., \& Chan, E. S. W. (2013). Coproduction versus co-creation: A process based continuum in the hotel service context. International Journal of Hospitality Management, 32, 11-20. https://doi.org/10.1016/J.IJHM.2012.03.009

Clark, B. Y., Brudney, J. L., Jakobsen, M., \& Andersen, S. C. (2013). Coproduction of Government Services and the New Information Technology: Inv...: EBSCOhost. Public Administration

Review, $73(5)$ $704-713$. https://doi.org/10.1111/puar.12092.Coproduction

Criado, I., \& Villodre, J. (2018). Public employees in social media communities: Exploring factors for internal collaboration using social network analysis. First Monday, 23(4).

Da Silva, C., \& Albano, C. (2017). Open data intermediaries: coproduction in budget transparency. Transforming Government: People, Process and Policy, 11(1), 119-131.

DonHee, L. (2017). A model for designing healthcare service based on the patient experience. International Journal of Healthcare Management, 1-7. 
European Commission. (2018). Co-production: Enhancing the role of citizens in governance and service delivery (Technical Dossier no. 4). Luxembourg.

Feller, J., Finnegan, P., \& Nilsson, O. (2011). Open innovation and public administration: Transformational typologies and business model impacts. European Journal of Information Systems, 20(3), 358-374.

Ferreira, E. (2017). The co-production of gender and ICT: Gender stereotypes in schools. First Monday, 22(10).

Fledderus, J. (2015). Building trust through public service co-production. International Journal of Public Sector Management, 28(7), 550-565.

Fledderus, J., \& Honingh, M. (2016). Why people co-produce within activation services: the necessity of motivation and trust - an investigation of selection biases in a municipal activation programme in the Netherlands. International Review of Administrative Sciences, 82(1), 69-87.

Gao, X. (2018). Networked Co-Production of 311 Services: Investigating the Use of Twitter in Five U.S. Cities. International Journal of Public Administration, 41(9), 712724.

Ghanbari, A., Laya, A., Alonso-Zarate, J., \& Markendahl, J. (2017). Business Development in the Internet of Things: A Matter of Vertical Cooperation. IEEE Communications Magazine, 55(2), 135-141. 
Granier, B., \& Kudo, H. (2016). How are citizens involved in smart cities? Analysing citizen participation in Japanese "Smart Communities". Information Polity, 21(1), 6176.

Gutiérrez, V., Theodoridis, E., Mylonas, G., Shi, F., Adeel, U., Diez, L., Muñoz, L. (2016). Co-creating the cities of the future. Sensors (Switzerland), 16(11).

Gutiérrez, V., Amaxilatis, D., Mylonas, G., \& Muñoz, L. (2018). Empowering citizens toward the Co-creation of Sustainable Cities. Internet of Things Journal, 5(2), 668-676.

Hardill, I., \& Mills, S. (2016). Enlivening evidence-based policy through embodiment and emotions. In Knowledge Mobilisation and the Social Sciences: Research Impact and Engagement (pp. 155-166).

Henwoord, F., \& Hart, A. (2003). Articulating gender in the context of ICTs in health care: The case of electronic patient records in the maternity services. Critical Social Policy, 23(2), 249-267.

Hilbert, M. (2011). Digital gender divide or technologically empowered women in developing countries? A typical case of lies, damned lies, and statistics. Women's Studies International Forum, 34(6), 479-489.

Ho, A. T.-K. (2002). Reinventing Local Governments and the E-Government Initiative. Public Administration Review, 62(4), 434-444. 
Huang, Y.-T. (2015). Participatory design to enhance ICT learning and community attachment: A case study in rural Taiwan. Future Internet, 7(1), 50-66.

Karahasanović, A., Brandtzæg, P. B., Heim, J., Lüders, M., Vermeir, L., Pierson, J., ... Jans, G. (2009). Co-creation and user-generated content-elderly people's user requirements. Computers in Human Behavior, 25(3), 655-678.

Khayyat, M., \& Bannister, F. (2017). Towards a model for facilitating and enabling cocreation using open government data. Information Polity, 22(4), 211-231.

Kinawy, S. N., El-Diraby, T. E., \& Konomi, H. (2018). Customizing information delivery to project stakeholders in the smart city. Sustainable Cities and Society, 38, 286-300.

King, S., \& Cotterill, S. (2007). Transformational Government? The role of information technology in delivering citizen-centric local public services. Local Government Studies, 33(3), 333-354.

Lecluijze, I., Penders, B., Feron, F. J. M., \& Horstman, K. (2015). Co-production of ICT and children at risk: The introduction of the Child Index in Dutch child welfare. Children and Youth Services Review, 56, 161-168.

Liberati, A., Altman, D. G., Tetzlaff, J., Mulrow, C., Gøtzsche, P. C., Ioannidis, J. P. Moher, D. (2009). The PRISMA statement for reporting systematic reviews and meta- 
analyses of studies that evaluate healthcare interventions: explanation and elaboration. BMJ (Clinical Research Ed.), 339.

Linders, D. (2012). From e-government to we-government: Defining a typology for citizen coproduction in the age of social media. Government Information Quarterly, $29(4), 446-454$.

Löbel, S., Paulowitsch, B., \& Schuppan, T. (2016). Intermediaries in the public sector and the role of information technology. Information Polity, 21(4), 335-346.

Maciulienè, M., \& Skarzauskienè. (2016). Evaluation of co-creation perspective in networked collaboration platforms. Journal of Business Research, 69(11), 4826-4830.

Maciulienè, M. (2018). Mapping digital co-creation for urban communities and public places. Systems, 6(2), 14.

Margetts, H., \& Dunleavy, P. (2002). Cultural barriers to e-government. Presented at the Better Public Services through e-government, National Audit Office Report by the Comptroller and Auditor General, HC 704-III Session 2001-2002, 4 April.

Mathis, E. F., Kim, H. (Lina), Uysal, M., Sirgy, J. M., \& Prebensen, N. K. (2016). The effect of co-creation experience on outcome variable. Annals of Tourism Research, 57, 62-75. https://doi.org/10.1016/J.ANNALS.2015.11.023 
Max-Neef, M. A. (2005). Foundations of transdisciplinarity. Ecological Economics, 53(1), 5-16.

Mayangsari, L., \& Novani, S. (2015). Multi-stakeholder co-creation Analysis in Smart city Management: An Experience from Bandung, Indonesia. Procedia Manufacturing, 4, $315-321$.

Medaglia, R. (2012). Engaged scholarship in research on information technology in government: Stuck in the Ivory Tower? Information Communication and Society, 246259.

Meijer, A. (2012). Co-production in an Information Age: Individual and Community Engagement Supported by New Media. Voluntas, 23(4), 1156-1172.

Meijer, A. (2014). New Media and the Coproduction of Safety. The American Review of Public Administration, 44(1), 17-34. https://doi.org/10.1177/0275074012455843.

Meijer, A. (2014). Organizational arrangements for targeted transparency. Information Polity, 19, 115-127.

Meijer, A. (2015). E-governance innovation: Barriers and strategies. Government Information Quarterly, 32(2), 198-206.

Millward, P. (2003). The "grey digital divide": Perception, exclusion and barriers of access to the Internet for older people. First Monday, 8(7). 
Moher, D., Liberati, A., Tetzlaff, J., Altman, D. G., \& The PRISMA Group. (2009). Preferred Reporting Items for Systematic Reviews and Meta-Analyses: The PRISMA Statement. PLoS Medicine, 6(7).

Muñoz-Erickson, T. A. (2014). Co-production of knowledge-action systems in urban sustainable governance: The KASA approach. Environmental Science and Policy, 37, $182-191$.

Musso, J. A., Young, M. M., \& Thom, M. (2019). Volunteerism as co-production in public service management: application to public safety in California. Public Management Review, 21(4), 473-494. https://doi.org/10.1080/14719037.2018.1487574.

Nambisan, S., \& Nambisan, P. (2017). How Should Organizations Promote Equitable Distribution of Benefits from Technological Innovation in Health Care? AMA Journal of Ethics, 19(11), 1106-1115.

OECD. (2018a). Transformative Technologies and Jobs of the Future: Background report for the Canadian G7 Innovation Ministers' Meeting.

OECD. (2018b). Embracing Innovation in Government: Global Trends 2018.

Osborne, S. P., Radnor, Z., \& Strokosch, K. (2016). Co-Production and the Co-Creation of Value in Public Services: A suitable case for treatment? Public Management Review, $18(5), 639-653$. 
Paletti, A. (2016). Co-production Through ICT in the Public Sector: When Citizens Reframe the Production of Public Services (pp. 141-152). Springer, Cham. https://doi.org/10.1007/978-3-319-40265-9_10

Parks, R. B., Baker, P. C., Kiser, L., Oakerson, R., Ostrom, E., Ostrom, V., ... Wilson, R. (1981). Consumers As Coproducers of Public Services: Some Economic and Institutional Considerations. Policy Studies Journal, 9(7), 1001-1011. https://doi.org/10.1111/j.1541-0072.1981.tb01208.x.

Porumbescu, G. A. (2016). Linking public sector social media and e-government website use to trust in government. Government Information Quarterly, 33(2), 291-304.

Prahalad, C. K., \& Ramaswamy, V. (2004). Co-creation experiences: The next practice in value creation. Journal of Interactive Marketing, 18(3), 5-14. https://doi.org/10.1002/DIR.20015.

Rodríguez Bolívar, M. P. (2015). The influence of political factors in policymakers' perceptions on the implementation of Web 2.0 technologies for citizen participation and knowledge sharing in public sector delivery. Information Polity, 20(2,3), 199-220. https://doi.org/10.3233/IP-150365.

Roussinos, D., \& Jimoyiannis, A. (2013). Analysis of students' participation patterns and learning presence in a wiki-based project. Educational Media International, 50(4), 306324. 
Szkuta, K., Pizzicannella, R., \& Osimo, D. (2014). Collaborative approaches to public sector innovation: A scoping study. Telecommunications Policy, 38(5-6), 558-567.

Thijssen, P., \& Van Dooren, W. (2015). Who you are/where you live: do neighbourhood characteristics explain co-production? International Review of Administrative Sciences, 82(1), 88-109.

Timmerman, J. G., Tönis, T. M., Dekker-Van, W., Stuiver, M. M., Wouters, M., Van Harten, H., Hermens, H. J. \& Vollenbroek-Hutten, M. M. R. (2016). Co-creation of an ICT-supported cancer rehabilitation application for resected lung cancer survivors: Design and evaluation. BMC Health Services Research, 16(1).

Torfing, J., Sørensen, E., \& Røiseland, A. (2016). Transforming the Public Sector Into an Arena for Co-Creation. Administration \& Society, 009539971668005. https://doi.org/10.1177/0095399716680057.

Torvinen, H., \& Ulkuniemi, P. (2016). End-user engagement within innovative public procurement practices: A case study on public-private partnership procurement. Industrial Marketing Management, 58, 58-68.

Trivellato, B. (2017). How can 'smart' also be socially sustainable? Insights from the case of Milan. European Urban and Regional Studies, 24(4), 337-351. 
Tursunbayeva, A., Franco, M., \& Pagliari, C. (2017). Use of social media for e-

Government in the public health sector: A systematic review of published studies. Government Information Quarterly, 34(2), 270-282.

Tuurnas, S. (2015). Learning to co-produce? The perspective of public service professionals. International Journal of Public Sector Management, 28(7), 583-598.

United Nations. (2016). The United Nations E-Government Survey 2016: E-Government in Support of Sustainable Development.

Uppström, E., \& Lönn, C.-M. (2017). Explaining value co-creation and co-destruction in e-government using boundary object theory. Government Information Quarterly, 34(3), $406-420$.

Van den Hazel, P., Keune, H., Randall, S., Yang, A., Ludlow, D., \& Bartonova, A. (2012). The challenge of social networking in the field of environment and health. Environmental Health: A Global Access Science Source, 11(SUPPL.1).

Van den Heerik, R. A. M., van Hooijdonk, C. M. J., Burgers, C., \& Steen, G. J. (2017). "Smoking Is Sóóó.. Sandals and White Socks": Co-Creation of a Dutch Anti-Smoking Campaign to Change Social Norms. Health Communication, 32(5), 621-628.

Van der Graaf, S., \& Veeckman, C. (2014). Designing for participatory governance: Assessing capabilities and toolkits in public service delivery. Info, 16(6), 74-88. 
Van Deursen, A. J. A. M., \& Van Dijk, J. A. G. M. (2011). Internet skills and the digital divide. New Media and Society, 13(6), 893-911.

Verschuere, B., Brandsen, T., \& Pestoff, V. (2012). Co-production: The State of the Art in Research and the Future Agenda. Voluntas, 23(4), 1083-1101. https://doi.org/10.1007/s11266-012-9307-8.

Voorberg, W. H., Bekkers, V. J. J. M., \& Tummers, L. G. (2015). A Systematic Review of Co-Creation and Co-Production: Embarking on the social innovation journey. Public $\begin{array}{llr}\text { Management } \quad \text { Review, } & 17(9),\end{array}$ https://doi.org/10.1080/14719037.2014.930505.

Webster, C. W. R., \& Leleux, C. (2018). Smart governance: Opportunities for technologically-mediated citizen co-production. Information Polity, 23(1), 95-110. https://doi.org/10.3233/IP-170065.

West, D. M. (2004). E-government and the transformation of service delivery and citizen attitudes. Public Administration Review, 64(1), 15-27.

Wildevuur, S. E., \& van Dijk, D. (2011). Scottie: Design for social connectedness in healthcare. CoDesign, 7(2), 131-138.

Williams, B. N., Kang, S.-C., \& Johnson, J. (2016). (Co)-Contamination as the Dark Side of Co-Production: Public value failures in co-production processes. Public Management Review, 18(5), 692-717. 
Yaraghi, N., Du, A. Y., Sharman, R., Gopal, R. D., \& Ramesh, R. (2015). Health information exchange as a multisided platform: Adoption, usage, and practice involvement in service co-production. Information Systems Research, 26(1), 1-18.

Yu, B., Ndumu, A., Mon, L., \& Fan, Z. (2018). An Upward Spiral Model: Bridging and Deepening Digital Divide (pp. 139-144). Springer, Cham. https://doi.org/10.1007/9783-319-78105-1_18 